\title{
The U.S. Nonfarm Payroll and the out-of-sample predictability of output growth for over six decades
}

\author{
Afees A. Salisu ${ }^{1,2} \cdot$ Abeeb Olaniran $^{3}$ \\ Accepted: 1 February 2022 / Published online: 13 February 2022 \\ (c) The Author(s), under exclusive licence to Springer Nature B.V. 2022
}

\begin{abstract}
We examine the predictive prowess of the U.S. Nonfarm Payroll (USNFP) for output growth in the U.S. covering over six decades from 1947 to 2021. Using two different measures of output growth (with Gross Domestic Product growth being used for the main analysis and growth in Industrial Production Index for robustness check), our predictability results show that the U.S. Nonfarm Payroll offers some predictive information for output growth in the U.S. and the out-of-sample forecast results equally attest to the superiority of the USNFP-based model over the model that ignores it. Our findings have implications for policy directions in the U.S. and various national and regional governments, multilateral agencies and investors whose economic and financial conditions are directly or indirectly linked with the U.S. economy.
\end{abstract}

Keywords U.S. Nonfarm Payroll · Output growth · Predictability · Forecast evaluation

JEL Classification C53 · E24 · O40

\section{Introduction}

In the midst of economic downturns, a healthy labour market ${ }^{1}$ indicated by rising employment is usually a pointer to output growth recovery (Course 2014). In this paper, we explore the predictive value of the United States Nonfarm Payroll (USNFP) - a measure of number of workers who actively participate in the production process ${ }^{2}$ - for output growth

\footnotetext{
1 The importance of labour market in an economy cannot be overemphasized as it accounts for more than half of the U.K's national income, for example (see Clancy 2009). Goulas and Zervoyianni (2018) equally attest to this for the OECD countries.

${ }^{2}$ https://fred.stlouisfed.org/series/PAYEMS

Afees A. Salisu

adebare1@yahoo.com

Abeeb Olaniran

olaniranabeeb464@gmail.com

1 Centre for Econometrics \& Applied Research, Ibadan, Nigeria

2 Department of Economics, University of Pretoria, Private Bag X20, Hatfield 0028, South Africa

3 Centre for Econometrics \& Applied Research, Ibadan, Nigeria
} 
of the country in question. The United States being a highly developed market economy, is the world's largest national economy in terms of GDP. Besides, it has the highest average household and employee income among OECD member states, which are pointers to a virile labour market. Therefore, any shock to this market is capable of impacting its production activities, and by extension, the economies of other countries of the world that are closely linked to it. This was particularly evident during the 2008 financial crisis, which began with the collapse of the U.S. housing market and quickly spread to the rest of the world. Thus, we hypothesize a positive nexus between the two variables (i.e. USNFP and output growth) following the modern theory of employment (see Wilson 1960; Basu and Foley 2013). Accordingly, an increase in the number of active workers (USNFP) would bring about a rise in aggregate demand via the income channel, which consequently improves output growth. In other words, higher (lower) incomes via additional (reduction in) jobs would lead to a rise (fall) in aggregate demand and by extension, an increase (a decrease) in investment in physical goods, hence growth (fall) in output level. The reason for a special focus on unemployment statistics is underscored by the signal it provides on the efficient utilization of resources which is necessary for growth in output (Blanchard and Johnson 2003). In addition, our underlying interest in exploring the out-of-sample predictability of USNFP for output growth lies in the evidence of moderate growth recorded in the U.S. economy whenever the former started to peak up (see Alguire 1996; Course 2014). Thus, we advance the literature to see if the information contained in the USNFP can be explored to improve the out-of-sample forecasts of output growth as limiting the analysis to impact assessment (that is, in-sample predictability) may not truly reflect the potential of realizing forecast gains when the USNFP is captured in the output growth projections (see Rapach and Zhou 2013). In implementing this objective and for the purpose of robustness checks, we opt for two different output measures (with Gross Domestic Product growth being used for the main analysis and growth in Industrial Production Index for robustness check) while we also account for relevant control variables such as oil (see, Cologni and Manera 2009; Ratti and Vespignani 2016; Koirala and Ma 2020, among others) and economic policy uncertainty index (see, Lensink et al. 1999; Kiesen 2013; Jovanovic and Ma 2021, among others) given their potential impact on the level of real economic activities. Finally, we employ the predictability approach of Westerlund and Narayan (2012, 2015) which accommodates salient features of both the predicted and predictor series in the estimation process, thus, improving the forecast outcomes. ${ }^{3}$

Lending credence to other studies on employment and growth nexus (see for example, Clancy 2009; Goulas and Zervoyianni 2018), our results show that USNFP predicts the output growth pretty well given the positive and statistical significance of the predictor parameter with or without controlling for oil price return and rate of change in the U.S. Economic Policy Uncertainty. This shows that the growth in output in the U.S. is a reflection of favourable conditions in the labour market. Similarly, our out-of-sample forecast evaluation results attest to the predictive value of a USNFP-based model in the output growth forecasts. Following this brief introduction, the remainder of this paper is structured as follows. Section II offers information about data and methodology while Section III describes the results. Section IV concludes.

\footnotetext{
${ }^{3}$ This approach has increasingly gained prominence in the literature involving predictability analysis (see for example, Bannigidadmath and Narayan 2015; Narayan and Bannigidadmath 2015; Narayan and Gupta 2015; Phan et al. 2015; Devpura et al. 2018; Salisu et al. 2019a, 2019b, Salisu and Sikiru 2020, among others).
} 
Table 1 Summary statistics and unit root tests

\begin{tabular}{lllllll}
\hline & Mean & SD & Skewness & Kurtosis & ADF & Nobs \\
\hline GDP_g & 0.7662 & 1.1630 & -1.3522 & 22.5068 & $-15.4665 * * *$ & 296 \\
IPI_g & 0.2291 & 1.0851 & -1.9448 & 36.3283 & $-20.7003 * * *$ & 888 \\
$\Delta$ USNFP & 0.1355 & 0.5651 & -16.3033 & 409.3153 & $-26.7396 * * *$ & 888 \\
\hline
\end{tabular}

IPI_g is the growth in Industrial Production Index, GDP_g means GDP growth both of which are proxies for output growth, and $\triangle$ USNFP is the percentage change in USNFP, a measure of active workers. Std. Dev. means standard deviation, Nobs. means number of observations and ADF is the Augmented Dickey-Fuller measure of unit root test reported in level, where the test equation includes trend and intercept

\section{Data and methodology}

\subsection{Data}

Our datasets consist of quarterly Gross Domestic Product (GDP) and the U.S. Nonfarm Payroll-USNFP over the period of 1947 and 2021 whose scope is governed by the available start date for GDP. The former is a measure of output growth as it covers all the sectors in an economy while the latter is a measure of active workers in the United States which excludes proprietors, private household employees, unpaid volunteers, farm employees, and the unincorporated self-employed). For the purpose of robustness, we also utilize data on U.S. Industrial Production Index (IPI) and since this variable is available at monthly frequency, we use the same for the empirical analysis. This additional analysis is crucial for two reasons: (i) we are able to test if the outcome will be sensitive to alternative measures of output growth (note that in standard growth literature involving a higher frequency than what is available for GDP growth, IPI growth is often used as a measure of real economic activity $)^{4}$; and (ii) we are also able to use a higher frequency data than that of GDP growth since monthly IPI data is available. We also account for two control variables namely oil price return and rate of change in U.S. economic policy uncertainty index (U.S. EPU). ${ }^{5}$ The latter only starts from 1985 and therefore, the estimation period is resized accordingly. All the variables are obtained from fred.stlouisfed.org which is freely accessible.

We render some preliminary statistics to understand the salient features of the series and for brevity, we limit this analysis to the variables of interest (GDP growth-GDP_g, IPI growth-IPI_g and the percentage change in USNFP - $\Delta$ USNFP). We focus on basic descriptive statistics such as the mean, standard deviation, skewness, kurtosis as well as a measure of unit root test of for relevant variables. From the Table 1, all the variables have a positive growth/return, with GDP_g and $\triangle$ USNFP having the highest and lowest growth

\footnotetext{
${ }^{4}$ New approaches of constructing indices for the level of real economic activities based on monthly frequency are gradually emerging (see for a review, Baumeister and Hamilton 2019), however, we do not intend to evaluate the performance of these indices, rather they are only relevant for robustness purpose for which the industrial production index serves.

${ }^{5}$ Economic Policy Uncertainty (EPU) index for the United States is based on newspaper coverage frequency. The monthly index relies on 10 leading newspapers, which serve as an anchor for digital archives from January 1985. The index uses monthly count of articles that contain either: 'uncertainty' or 'uncertain'; 'economic' or 'economy'; and one of the following policy terms: 'congress', 'deficit', 'Federal Reserve', 'legislation', 'regulation' or 'white house'—including variants like 'uncertainties', 'regulatory' or 'the Fed' (see Baker et al. 2016).
} 


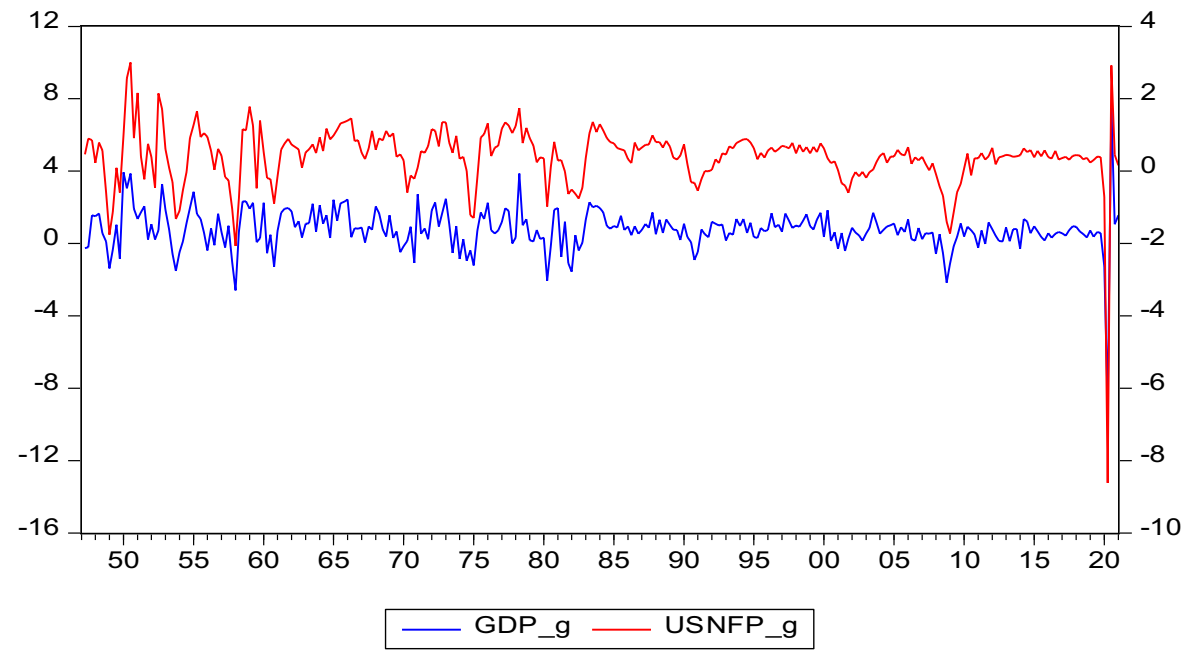

Fig. 1 Co-movement of percentage changes in U.S. Nonfarm Payroll ( $\Delta$ USNP) and GDP growth (GDP_g)

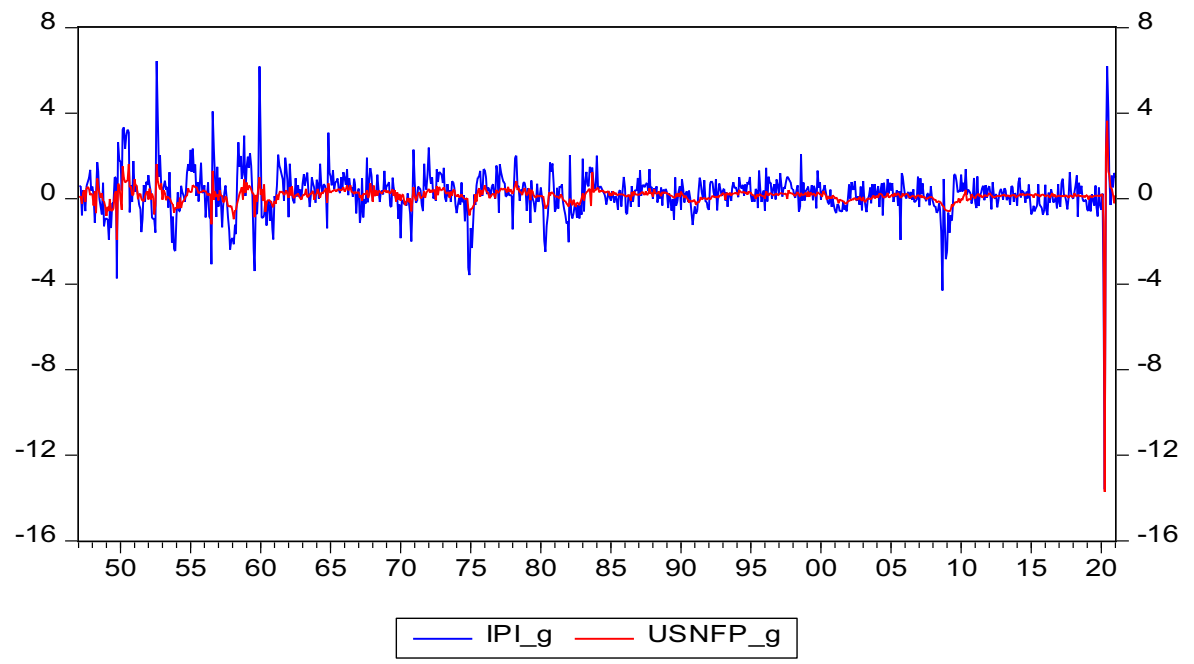

Fig. 2 Co-movement of percentage changes in U.S. Nonfarm Payroll ( $\Delta$ USNP) and IPI growth (IPI_g)

averages, respectively. Similarly, all the variables are negatively skewed while the kurtosis statistics suggests that all the variables in their growth/return forms are leptokurtic, denoting that they are heavily tailed. Furthermore, the statistical significance at one percent, of our ADF unit root test indicates that all our variables are stationary at level.

Finally, on the co-movement between the measures of output growth and growth in USNFP, Figs. 1 and 2 below show a positive relationship between output growth (whether GDP_g or IPI_g) and $\Delta$ USNFP. This suggests that an increase in USNFP, a measure of employment, brings about an increase in GDP_g and IPI_g, both of which are a measure of output growth. This connection between employment and output growth is well entrenched 
in the modern theory of employment albeit without evidence for its out-of-sample predictive value (see Wilson 1960; Basu and Foley 2013). We further employ a formal test to establish the in-sample cointegration between the two variables using the familiar Bounds cointegration test and the results are presented in the appendix (see Tables 5 and 6). We are able to offer a formal evidence for the co-movement between USNFP and output growth as the null of hypothesis of no cointegration is rejected at all the conventional levels of statistical significance. In the next section, we extend the analysis to the out-of-sample predictability of a USNFP-based output growth model in order to offer a more insightful policy implications of our findings.

\section{Methodology}

Relying on the modern theory of employment, where the argument of increased utilization of any resource leads to rise in production of physical goods is presented (see Wilson 1960), we construct a predictive model in order to establish the predictive value of USNFP in the out-of-sample predictability of output growth:

$$
\text { Growth }_{t}=\alpha+\beta \Delta \text { USNFP }_{t-1}+\text { Control }_{t-1}+\varepsilon_{t}
$$

where Growth $_{t}$ is the output growth, $\triangle U S N F P$ is the percentage change in US Nonfarm Payroll, a measure of active workers in employment, all computed as $100^{*} \Delta \log \left(y_{t}\right)$ where $y_{t}$ is the level series; $\alpha$ being the intercept; Control represents the control variables namely oil return computed as log return of oil price using West Texas Intermediate crude oil price, and rate of change in U.S. Economic Policy Uncertainty while $\varepsilon_{t}$ is the zero mean idiosyncratic error term. Similarly, $\beta$ shows the response of growth in output to employment growth. ${ }^{6}$ Furthermore, to resolve the issue of conditional heteroscedasticity effect in the error term, we pre-weight all the data with the inverse of the standard deviation $1 / \hat{\sigma}_{t}^{2}$ obtained from a typical GARCH-type model and thereafter estimate the resulting equation with the OLS (see Westerlund and Narayan 2012, 2015).

Finally, we extend our predictive model as presented in Eq. (1) to include the out-ofsample period and, thereafter, we compare the forecast performance of the USNFP-based model (for both with and without control) with a benchmark model (historical average), using the relative root mean square error (RRMSE) and the Clark and West (2007) [CW] test. The RRMSE is computed as the ratio of RMSE of the USNFP-based model in Eq. (1) to that of the benchmark model, such that a value less (greater) than one is considered to indicate superior (inferior) performance of the former over the latter. The CW test suitable for nested models is a one-sided test and it is used to determine the difference in the forecast errors of the two competing models where the null hypothesis of a zero coefficient is rejected if the t-statistic is greater than +1.282 (for a one sided 0.10 test),+1.645 (for a one sided 0.05 test), and +2.00 for 0.01 test (for a one sided 0.01 test). The forecast analysis is rendered for multiple out-of-sample (i.e., 1-month, 6-month, 12-month and 24-month; and 1- quarter, 4-quarter, 8-quarter and 12-quarter) ahead forecast horizons, while the 75:25 data split is respectively used for the in-sample and out-of-sample forecasts.

\footnotetext{
${ }^{6}$ There are three possibilities of $\beta$ : (i) when the coefficient is greater than 0 (output growth increases with changes in USNFP); (ii) when the coefficient is less than 0 (output growth reduces with changes in USNFP); and (iii) when the coefficient is equal to 0 (output growth remains constant with changes in USNFP) (see Salisu and Sikiru 2020; Salisu et al. 2020).
} 
Table 2 Predictability results for output growth

\begin{tabular}{lll}
\hline Model & GDP (1947Q1-2021Q1) & IPI (1947M01-2021M01) \\
\hline Without control & $0.63060^{\mathrm{a}}$ & $0.6863^{\mathrm{a}}$ \\
& $(0.0513)$ & $(0.0974)$ \\
With control (oil) & $0.6861^{\mathrm{a}}$ & $0.6245^{\mathrm{a}}$ \\
& $(0.0743)$ & $(0.1029)$ \\
\hline Model & GDP $(1985 \mathrm{Q} 1-2021 \mathrm{Q} 1)$ & IPI (1985M01-2021M01) \\
\hline With control (EPU) & $0.5773^{\mathrm{a}}$ & $0.6689^{\mathrm{a}}$ \\
& $(0.0482)$ & $(0.1361)$ \\
\hline
\end{tabular}

In this table, reported estimates are the slope coefficients of the predictor variable-U.S. Nonfarm Payroll (USNFP), while the values in parentheses are the corresponding standard errors. Model without control indicates an unadjusted model, while model with control is adjusted for oil price and EPU (US Economic Policy Uncertainty) distinctly. "a" indicates statistical significance at $1 \%$. Hence, significance indicates a case of predictability; otherwise, it is a case of no predictability

\section{Results and discussion}

\subsection{Main findings}

We begin the discussion of results by presenting the in-sample predictability of U.S. Nonfarm Payroll (USNFP) for GDP growth where we are able to determine the direction of relationship between the two variables (see Table 2 for the results with and without the control variables). Expectedly, we find evidence of a positive and statistically significant relationship between USNFP and GDP growth indicating that an increase in the non-farm labour market improves the productivity of the U.S. economy. In other words, when the USNFP, a measure of U.S. labour market condition, rises, the GDP growth in the U.S. follows suit. This supports our hypothesis which hinges on the modern theory of employment-postulating a positive relationship between the employment and growth. We also offer additional results by extending the predictive model of GDP growth to capture other important determinants of growth such as oil and policy uncertainty indices based on the U.S. Economic Policy Uncertainty. These additional predictors are distinctly captured in the regression models and the results are also embedded in Table 2 with those that do not account for the control variables for easy comparison. We observe that the sign and significance of the USNFP remain the same even after controlling for other predictors. In other words, the results are robust to alternative specifications for the growth model.

Consequently, we extend our analysis to include the out-of-sample forecast performance of our proposed USNFP-based growth model since the presence of in-sample predictability between the two variables does not necessarily guarantee out-of-sample forecast gains. As noted in the methodology and for the purpose of emphasis, we state again how the out-of-sample forecast is carried out. We conduct this analysis by comparing the out-of-sample forecast performance of the USNFP-based growth model with that of the benchmark (historical average) model using the relative root mean square error and Clark and West (2007) test. The results of the relative root mean square error presented in Table 3 whose values must be less than unity for the USNFP-based model to outperform the benchmark (historical average) model consistently favour the former. The difference in the forecast errors between these two competing models is evaluated 
Table 3 Forecast evaluation using relative RMSE

\begin{tabular}{|c|c|c|c|c|c|c|c|c|}
\hline & \multicolumn{4}{|c|}{ GDP growth } & \multicolumn{4}{|c|}{ IPI growth } \\
\hline & $\mathrm{h}=1$ & $\mathrm{~h}=4$ & $\mathrm{~h}=8$ & $\mathrm{~h}=12$ & $\mathrm{~h}=1$ & $h=6$ & $\mathrm{~h}=12$ & $\mathrm{~h}=24$ \\
\hline Without control & 0.6802 & 0.6753 & 0.6728 & 0.6674 & 0.8713 & 0.8697 & 0.8664 & 0.8611 \\
\hline With control (oil) & 0.5541 & 0.5494 & 0.5475 & 0.5432 & 0.8835 & 0.8817 & 0.8783 & 0.8729 \\
\hline With control (EPU) & 0.8586 & 0.8592 & 0.8750 & 0.8921 & 0.9786 & 0.9796 & 0.9809 & 0.9831 \\
\hline
\end{tabular}

The analysis for models with GDP growth involves quarterly frequency while the one of IPI growth involves monthly frequency. With the exception of models with EPU, the analyses cover the period of 1947-2021. Those with EPU cover the period of 1985-2021 due to the start date for the series in question. The relative RMSE (RRMSE) is computed as the ratio of RMSE of the USNP-based model to that of the benchmark (historical) model, such that a value less (greater) than one is considered to indicate superior (inferior) performance of the former over the latter

Table 4 Forecast evaluation using Clark and West test

\begin{tabular}{|c|c|c|c|c|c|c|c|c|}
\hline & \multicolumn{4}{|c|}{ GDP growth } & \multicolumn{4}{|c|}{ IPI growth } \\
\hline & $\mathrm{h}=1$ & $\mathrm{~h}=4$ & $\mathrm{~h}=8$ & $\mathrm{~h}=12$ & $\mathrm{~h}=1$ & $h=6$ & $\mathrm{~h}=12$ & $\mathrm{~h}=24$ \\
\hline Without control & $\begin{array}{l}0.3337^{\mathrm{a}} \\
{[5.0484]}\end{array}$ & $\begin{array}{l}0.3317^{\mathrm{a}} \\
{[5.0870]}\end{array}$ & $\begin{array}{l}0.3248^{\mathrm{a}} \\
{[5.0630]}\end{array}$ & $\begin{array}{l}0.3192^{\mathrm{a}} \\
{[5.0583]}\end{array}$ & $\begin{array}{l}0.1360^{\mathrm{a}} \\
{[4.6751]}\end{array}$ & $\begin{array}{l}0.1353^{\mathrm{a}} \\
{[4.6831]}\end{array}$ & $\begin{array}{l}0.1340^{\mathrm{a}} \\
{[4.6808]}\end{array}$ & $\begin{array}{l}0.1318^{\mathrm{a}} \\
{[4.6810]}\end{array}$ \\
\hline With control (oil) & $\begin{array}{l}0.4612^{\mathrm{a}} \\
{[5.0658]}\end{array}$ & $\begin{array}{l}0.4584^{\mathrm{a}} \\
{[5.1026]}\end{array}$ & $\begin{array}{l}0.4501^{\mathrm{a}} \\
{[5.0954]}\end{array}$ & $\begin{array}{l}0.4423^{\mathrm{a}} \\
{[5.0904]}\end{array}$ & $\begin{array}{l}0.1238^{\mathrm{a}} \\
{[4.6730]}\end{array}$ & $\begin{array}{l}0.1232^{\mathrm{a}} \\
{[4.6848]}\end{array}$ & $\begin{array}{l}0.1222^{\mathrm{a}} \\
{[4.6851]}\end{array}$ & $\begin{array}{l}0.1201^{\mathrm{a}} \\
{[4.6826]}\end{array}$ \\
\hline With control (EPU) & $\begin{array}{l}0.1985^{a} \\
{[3.7274]}\end{array}$ & $\begin{array}{l}0.1932^{\mathrm{a}} \\
{[3.7331]}\end{array}$ & $\begin{array}{l}0.1804^{\mathrm{a}} \\
{[3.5878]}\end{array}$ & $\begin{array}{l}0.1595^{\mathrm{a}} \\
{[3.5392]}\end{array}$ & $\begin{array}{l}0.0539^{\mathrm{a}} \\
{[4.3371]}\end{array}$ & $\begin{array}{l}0.0528^{\mathrm{a}} \\
{[4.3012]}\end{array}$ & $\begin{array}{l}0.0514^{\mathrm{a}} \\
{[4.2490]}\end{array}$ & $\begin{array}{l}0.0491^{\mathrm{a}} \\
{[4.1871]}\end{array}$ \\
\hline
\end{tabular}

The values reported in square brackets are the t-statistics. The null hypothesis of a zero coefficient is rejected if the $\mathrm{t}$-statistic is greater than +1.282 (for a one sided 0.10 test),+1.645 (for a one sided 0.05 test), and +2.00 (for a one sided 0.01 test) (see Clark and West 2007). "a" indicates statistical significance at $1 \%$. Model without control indicates an unadjusted model, while model with control is adjusted for oil price. Also, positive and significant values indicate that the USNFP-based model beats the benchmark (historical average) model

using the Clark and West (2007) test and the results presented in Table 4 affirm the superiority of the USNFP-based growth model over the model that ignores the predictive value of USNFP in the out-of-sample forecast of U.S. GDP growth. As previously noted, we also consider the IPI growth for robustness purpose. We further note in the previous section that this consideration is important for two reasons. First, we are able to test if the outcome will be sensitive to alternative measures of output growth (note that in standard growth literature involving a higher frequency than what is available for GDP growth, IPI growth is often used as a measure of real economic activity). Second, we are also able to use a higher frequency data than that of GDP growth since monthly IPI data is available. The in-sample predictability results obtained for the IPI growth are also embedded in Table 2 and interestingly, the magnitudes and signficance of the predictor series (USNFP) for the alternative specification are similar to that of GDP growth, thus attesting to the robustness of the predictability outcomes. This conclusion about the similarity in the results of both GDP growth and IPI growth is also observed for the out-of-sample predictability analysis (se Tables 3 and 4). Thus, regardless of the choice of output growth governed by data frequency, the predictive 
value of U.S. Non-Farm Payroll in output growth forecast is significant both for the in-sample and out-of-sample periods. Our results also align well with the findings of Course (2014) and Goulas and Zervoyianni (2018), although these studies are limited to in-sample predictability (that is, impact analysis).

Several policy implications can be discerned from the study outcomes and we highlight a number of them as follows. First, the evidence here supports a strong connection between the labour market and the real sector of the economy (since industrial production index as used in this study is a good measure of real sector productivity) and it particularly suggests that an improvement in the labour market is an indication of a vibrant real sector which equally reverberates across the larger economy, thus translating into higher economic growth (judging by the significantly positive connection between USNFP and GDP growth-a measure of aggregate productivity growth which is larger in scope than the IPI growth). Second and flowing from the first implication, a more accurate forecast of U.S. output growth can be achieved with the inclusion of USNFP among other relevant predictors. This outcome is useful in fiscal budgeting where output growth forecast serves as one of the benchmarks for its implementation and the more realistic is the forecast, the higher the development outcomes associated with such a budget. Finally, given the strategic position of the U.S. in the global economy, information about its growth forecast is not only used by the domestic economy but also often required by various national and regional governments, multilateral agencies and investors whose economic and financial conditions are directly or indirectly linked with the U.S. economy. In sum, the need to constantly revise the U.S. growth models to improve their forecasts is important from both investment and policy perspectives and we hope our study offers a useful guide in this regard.

\section{Conclusion}

Exploring the predictive prowess of USNFP - a measure of the number of active United States workers-for output growth cannot have a better timing than now with the increasing concern to revive the global economy from the grip of coronavirus pandemic. Unlike other studies that have explored the effect of output growth on employment, we show that employment equally possesses some predictive contents for output growth. Exploiting the information contained in the USNFP, we find that the latter does not only predict output growth for the U.S., but also have a positive effect on it, confirming the a priori as espoused in the modern theory of employment. In other words, accounting for the predictive value of labour market dynamics in the U.S. may improve the accuracy of output growth projections. This shows that the growth in output in the U.S. mirrors a favorable condition in the labour market. Thus, policy directions geared towards strengthening the labour market have ripple effects on the macro economy and more importantly, the labour market dynamics have predictive value that can serve as a barometer for measuring economic progress and by extension output growth. It would be nice to see how the U.S. labour market connects with the financial markets subject to data availability. This should further provide information as regards whether the USNFP can serve as a good measure of economic conditions in the U.S. such that job gains (losses) can be seen to imply improvement (deterioration) in the financial markets. 


\section{Appendix}

See Tables 5 and 6.

Table 5 F-Bounds test for GDP_g and USNFP_g

\begin{tabular}{lllll}
\hline Test statistic & Value & Sig & $\mathrm{I}(0)$ & $\mathrm{I}(1)$ \\
\hline F-statistic & 130.873 & $10 \%$ & 3.02 & 3.51 \\
& & $5 \%$ & 3.62 & 4.16 \\
& & $2.50 \%$ & 4.18 & 4.79 \\
& & $1 \%$ & 4.94 & 5.58 \\
\hline
\end{tabular}

F-Bounds Test for co-integration is based on restricted constant and no trend, and lags are generated automatically. The null hypothesis of no co-integration is rejected if the F-Statistic value is greater than the critical value at either $10 \%, 5 \% 2.5 \%$ or $1 \%$ for upper bound $[\mathrm{I}(0)]$. Otherwise, there is no co-integration, and the null hypothesis will not be rejected. GDP_g means Gross Domestic Product growth while USNFP is the United States' Non-Farm Payroll which is a measure of active workers

Table 6 F-Bounds Test for IPI_g and USNFP_g

\begin{tabular}{lllll}
\hline Test statistic & Value & Sig & $\mathrm{I}(0)$ & $\mathrm{I}(1)$ \\
\hline F-statistic & \multirow{2}{*}{64.82798} & $10 \%$ & 3.02 & 3.51 \\
& & $5 \%$ & 3.62 & 4.16 \\
& $2.50 \%$ & 4.18 & 4.79 \\
& $1 \%$ & 4.94 & 5.58 \\
\hline
\end{tabular}

F-Bounds Test for co-integration is based on restricted constant and no trend, and lags are generated automatically. The null hypothesis of no co-integration is rejected if the F-Statistic value is greater than the critical value at either $10 \%, 5 \% 2.5 \%$ or $1 \%$ for upper bound [I(0)]. Otherwise, there is no co-integration, and the null hypothesis will not be rejected. IPI_g means Industrial Production Index growth while USNFP is the United States' Non-Farm Payroll which is a measure of active workers

Author contributions AS: Conceptualization, Writing of the manuscript, Methodology, Formal Analysis, Results Validation, Reviewing and Editing. AO: Conceptualization, Methodology, Formal Analysis, Software, Writing—Original Draft, Reviewing \& Editing.

Funding No specific financial support was received to carry out the study.

Availability of data and material The data that support the findings of this study are available on FRED Economic data of St. Louis using the https://fred.stlouisfed.org.

Code availability The codes used for analysis can be made available by the authors on request. 


\section{Declarations}

Conflict of interest The authors do not have any conflict of interest to declare.

\section{References}

Alguire, M.S.: Nonfarm payroll jobs in Arkansas and the nation continue to increase. Ark. Bus. Econ. Rev. 29(1), 26 (1996)

Baker, S.R., Bloom, N., Davis, S.J.: Measuring economic policy uncertainty. Q. J. Econ. 131(4), 1593-1636 (2016)

Bannigidadmath, D., Narayan, P.: Stock return predictability and determinants of predictability and profits. Emerg. Mark. Rev. 26, 153-173 (2015)

Basu, D., Foley, D.K.: Dynamics of output and employment in the US economy. Camb. J. Econ. 37(5), 10771106 (2013)

Baumeister, C., Hamilton, J.D.: Structural interpretation of vector autoregressions with incomplete identification: Revisiting the role of oil supply and demand shocks. Am. Econ. Rev. 109(5), 1873-1910 (2019)

Blanchard, O., Johnson, D.R.: Macroeconomics, 6th edn. Pearson, New York (2003)

Clancy, G.: The labour market and the economy 20 years reviewed. Econ. Labour Mark. Rev. 3(2), 17-20 (2009)

Clark, T.E., West, K.D.: Approximately normal tests for equal predictive accuracy in nested models. J. Econom. 138(1), 291-311 (2007). https://doi.org/10.1016/j.jeconom.2006.05.023

Cologni, A., Manera, M.: The asymmetric effects of oil shocks on output growth: a Markov-switching analysis for the G-7 countries. Econ. Model. 26(1), 1-29 (2009)

Course, L.M.F.M.: Output growth likely to rebound amid a healthy labor market. Econ. Indic. (2014)

Devpura, N., Narayan, P.K., Sharma, S.S.: Is stock return predictability time-varying? J. Int. Financ. Mark. Inst. Money 52, 152-172 (2018)

Goulas, E., Zervoyianni, A.: Active labour-market policies and output growth: is there a causal relationship? Econ. Model. 73, 1-14 (2018)

Jovanovic, B., Ma, S.: Uncertainty and growth disasters. Rev. Econ. Dyn. (2021). https://doi.org/10.1016/j.red. 2021.04.002

Kiesen, K.: Uncertainty and the Economy. Federal Reserve Bank of St. Louis (2013). https://www.stlouisfed. org/publications/regional-economist/april-2013/uncertainty-and-the-economy

Koirala, N.P., Ma, X.: Oil price uncertainty and US employment growth. Energy Econ. 91, 104910 (2020)

Lensink, R., Bo, H., Sterken, E.: Does uncertainty affect economic growth? An empirical analysis. Weltwirtschaftliches Archiv 135(3), 379-396 (1999)

Narayan, P.K., Bannigidadmath, D.: Are Indian stock returns predictable? J. Bank. Financ. 58, 506-531 (2015)

Narayan, P.K., Gupta, R.: Has oil price predicted stock returns for over a century? Energy Econ. 48, 18-23 (2015)

Phan, D.H.B., Sharma, S.S., Narayan, P.K.: Stock return forecasting: some new evidence. Int. Rev. Financ. Anal. 40, 38-51 (2015)

Rapach, D., Zhou, G.: Forecasting stock returns. In: Handbook of Economic Forecasting, vol. 2, pp. 328-383 (2013)

Ratti, R., Vespignani, J.L.: Oil prices and global factor macroeconomic variables. Energy Econ. 59, 198-212 (2016)

Salisu, A.A., Sikiru, A.A.: Pandemics and the Asia-Pacific Islamic stocks. Asian Econ. Lett. 1(1), 17413 (2020). https://doi.org/10.46557/001c.17413

Salisu, A.A., Swaray, R., Oloko, T.F.: Improving the predictability of the oil-US stock nexus: the role of macroeconomic variables. Econ. Model. 76, 153-171 (2019a)

Salisu, A.A., Raheem, I.D., Ndako, U.B.: A sectoral analysis of asymmetric nexus between oil price and stock returns. Int. Rev. Econ. Financ. 61(C), 241-259 (2019b)

Salisu, A.A., Raheem, I.D., Eigbiremolen, G.O.: The behaviour of US stocks to financial and health risks. Int. J. Financ. Econ. (2020). https://doi.org/10.1002/ijfe.2390

Westerlund, J., Narayan, P.K.: Does the choice of estimator matter when forecasting returns? J. Bank. Financ. 36(9), 2632-2640 (2012). https://doi.org/10.1016/j.jbankfin.2012.06.005

Westerlund, J., Narayan, P.K.: Testing for predictability in conditionally heteroskedastic stock returns. J. Financ. Econom. 13(2), 342-375 (2015). https://doi.org/10.1093/jjfinec/nbu001

Wilson, G.W.: The relationship between output and employment. Rev. Econ. Stat. 42, 37-43 (1960) 
Publisher's Note Springer Nature remains neutral with regard to jurisdictional claims in published maps and institutional affiliations. 